\title{
The evolutionary history of Drosophila buzzatii. XXV. Random mating in nature
}

\author{
JORGE E. QUEZADA-DÍAZ, MAURO SANTOS, ALFREDO RUIZ \& \\ ANTONIO FONTDEVILA \\ Departamento de Genética y Microbiologia, Universidad Autónoma de Barcelona, 08193 Bellaterra (Barcelona), Spain
}

\begin{abstract}
Using allozymes as the genetic probe, data are presented which show that wild Drosophila buzzatii females and males engaged in copulation mate at random. Hence, putative inbreeding due to local mating of genetically related flies emerging from the patchy distributed substrates, was not detected. We conclude that individuals raised from a niche disperse and mate at random with other members of the population, so only one round of drift due to the colonization of suitable and ephemeral breeding sites is taking place.
\end{abstract}

Keywords: allozymes, breeding sites, cactophilic Drosophila, mating pattern, natural population, population structure.

\section{Introduction}

Mating pattern refers to choice of mate and is one of the three main components of mating behaviour besides male and female differential mating success (Lewontin et al., 1968; Anderson \& McGuire, 1978; Alvarez \& Fontdevila, 1981; Santos et al., 1986). Albeit not a selective component by itself, mating pattern links genotypic frequencies across generations and subsequent gene and gametic frequency changes induced by selection will be dependent on input genotypes. Random mating, which can be loosely defined as the absence of any tendency for certain kinds of males and females to pair, when considered with respect to a particular trait' (Falk \& Ehrman, 1973), is the simplest pattern of mating and is usually assumed in most population genetic models. Even in some genetic models of sexual selection that involve differential mating success in one sex due to preferences exhibited by the other sex, there are not deviations from random mating (O'Donald, 1980).

Two kinds of departure from random mating have been classically considered by many authors: assortative mating and inbreeding. There is a distinguishing feature between them, i.e. assortative mating with or without differential mating success is characterspecific, whereas deviations from random mating due to inbreeding are not specific to particular traits but affect all loci in a uniform way. In nature inbreeding may occur wherever the population is spatially structured. The cactophilic fly Drosophila buzzatii feeds and breeds upon the micro-organisms associated with the decaying Opuntia (prickly pear) tissues which constitute an ephemeral and patchy resource (Barker, 1977; Santos et al., 1989). The number of parents breeding on a single rot is limited (approximately 10; Santos et al., 1989; Thomas \& Barker, 1990), and it has been suggested that inbreeding may be relatively common in D. buzzatii and other cactophilic species of the repleta group because newly emerged flies from a breeding site, which are more closely related than flies taken at random from the whole population, are more likely to mate with each other (Thomas \& Barker, 1990). The purpose of this paper is to test whether or not deviations from random mating are the norm in D. buzzatii.

Most tests for the null hypothesis of random mating, or independence of the parents' probabilities of transmitting genes, are based on the fit of observed genotypic frequencies to Hardy-Weinberg proportions. Nevertheless, it is well known that these are indirect tests and cannot be taken as evidence of random mating because their power to detect departures from Hardy-Weinberg, due to inbreeding (Ward \& Sing, 1970 ) or selection (Lewontin \& Cockerham, 1959), is weak (see also Brown, 1970) and, what is more striking, random union of gametes is not equivalent to random mating ( $\mathrm{Li}, 1988$; Tai, 1990). Hence, it is necessary to determine the genotypes of the mating 
pairs and this can be accomplished either by collecting mother-offspring genotype combinations or by sampling directly both partners. The second procedure can also be used for quantitative traits (Partridge et al., 1987; Santos et al., 1988, 1992). However, both methods are not equivalent as concurrent multiple paternity has been described in many organisms including several Drosophila species (Anderson, 1974; Milkman \& Zeitler, 1974, Cobbs, 1977; Gromko et al., 1980; Levine et al., 1980; Loukas et al., 1981), and it would be difficult, for autosomal loci, to distinguish between mating by two homozygous or a single heterozygous male. Consequently, sampling mating pairs in nature seems to be the most accurate method and is the one used in this paper.

\section{Materials and methods}

The present study was carried out in the early summer of 1987 (25-29 June) and in the late spring of 1989 (16-20 June) in an old Opuntia ficus-indica plantation located at Carboneras, which has been described elsewhere (Ruiz et al., 1986). No rotting O. ficus-indica fruits were present in the sampling area at the time of collection, so $D$. buzzatii flies were feeding and breeding exclusively on rotting cladodes. Sampling procedures were the same in both years and full details are given in Santos et al. (1988, 1992). Briefly, the flies attracted to the daily collected rots were observed and mating pairs were gently aspirated by use of a tube operated by mouth-suction. The number of mating pairs sampled was 396 in 1987 and 386 in 1989. Within the next $3 \mathrm{~h}$ after collection the flies were separated by sex and individually mated to virgin flies of a laboratory stock to ascertain their karyotype (Ruiz et al., 1991). After approximately 2 weeks, thorax length measurements were carried out and the flies were frozen at $-20^{\circ} \mathrm{C}$ for later starch gel electrophoresis.

Each adult was assayed for two polymorphic enzyme loci (Pept-2 and Adh-1) in 1987 and four (Est2, Pept-2, Aldox and Adh-1) in 1989. Details of the electrophoretic procedures are given in Loukas \& Krimbas (1980) for Pept-2 and in Barker \& Mulley (1976) and Barker et al. (1986) for the other three. All four loci are autosomal and linkage studies have shown that Est-2 and Aldox are linked to the inversions on the second chromosome, whereas Pept-2 is outside the inverted fragments (J. E. Quezada-Diáz et al., unpublished results; see also Knibb et al., 1987 and Thomas \& Barker, 1990). Adh-1 (closely linked to locus Adh-2; see Oakeshott et al., 1982 and Alberola et al., 1987) maps at the G1a band of the third chromosome as deduced from the strong signal obtained by in-situ hybridization with a fragment containing the $A d h$ gene of D. melanogaster (Labrador et al., 1990). In Carboneras, Est-2 segregates for four alleles, and the other three loci segregate for two alleles each (see Table 1). The nomenclature used for Est-2, Aldox, and Adh-1 alleles is that given in Barker \& Mulley (1976) and Barker et al. (1986) and was standardized by using $D$. buzzatii stocks kindly sent to us by Professor J. S. F. Barker. The same standard nomenclature was used for Pept-2; i.e. Pept-1 (monomorphic in this population) encoded for a faster migrating protein than Pept-2, and Pept $-2^{a}$ allele encoded for a faster migrating protein than Pept-2 ${ }^{b}$. Alleles Est-2 $2^{b}, E s t-2^{c}$ and Est-2 ${ }^{d}$ were pooled into a single class for statistical analyses.

Three-way contingency tables per locus and year were obtained and statistically analysed with respect to the following variables: day of sampling $(\alpha)$, female genotype $(\beta)$, and male genotype $(\gamma)$. The data were fit to a series of log-linear models (see Bishop et al., 1975) and a brief description follows.

The saturated log-linear model for a three-dimensional table is:

$\ln f_{i j k}=\mu+\alpha_{\imath}+\beta_{j}+\gamma_{k}+\alpha \beta_{i j}+\alpha \gamma_{i k}+\beta \gamma_{j k}+\alpha \beta \gamma_{i j k}$,

where $f_{i j k}$ is the expected frequency in row $i$, column $j$, depth $k$ of the three-way contingency table, and $\mu$ is the mean of the logarithms of the expected frequencies. This model includes the main effect parameters together with first-order $\left(\alpha \beta_{i j}, \alpha \gamma_{i k}, \beta \gamma_{j k}\right)$ and secondorder $\left(\alpha \beta \gamma_{i j k}\right)$ effects. A set of hierarchical models from the simplest one (without two-factor and, by implication, three-factor effects) to the above saturated one can be chosen for fitting to the observed data. Our main goal in the present paper is to test for departures from random mating (i.e. to test for the null hypothesis $H_{0}: \beta \gamma_{j k}=0$ for all $j k$ ), and the following log-linear models were used:

Model 1: $\ln f_{i j k}=\mu+\alpha_{i}+\beta_{j}+\gamma_{k}$, Model 2: $\ln f_{i j k}=\mu+\alpha_{i}+\beta_{j}+\gamma_{k}+\beta \gamma_{j k}$.

The three variables are completely independent in model 1 , whereas variable $\alpha$ is independent of the other two, which are associated with each other, in model 2. In our data, agreement with model 2 would mean that both male and female genotype distributions were similar among days, but observed cell frequencies for female-male genotype combinations were different to their expectations based on marginal frequencies, i.e. there was no random mating.

Two other models ( 3 and 4) can be used to test for heterogeneity of genotypic frequencies among days in females (some $\alpha \beta_{i j} \neq 0$ ), and males (some $\alpha \gamma_{i k} \neq 0$ ), 
respectively:

Model 3: $\ln f_{i j k}=\mu+\alpha_{i}+\beta_{j}+\gamma_{k}+\alpha \beta_{i j}$,

Model 4: $\ln f_{i j k}=\mu+\alpha_{i}+\beta_{j}+\gamma_{k}+\alpha \gamma_{i k}$.

To test for the significance of a term in the log-linear model the corresponding $G$-statistic is computed as the difference between the $G$-values corresponding to two of the models: one with the term present and one with it left out (Sokal \& Rohlf, 1981). Data manipulation and analyses were accomplished on a Vax-8800 VMS at the Centro de Cálculo de la Universidad Autónoma de Barcelona. The statistical programs used were part of the BMDP Statistical Software (1988).

\section{Results}

The total number of mating females and males assayed per locus and year, together with allele frequencies and departures from Hardy-Weinberg proportions $(D$-value or one-locus disequilibria; see Weir, 1990), are given in Table 1. Pept-2 showed a statistically significant heterozygote deficiency in females in 1989, whereas an excess of heterozygotes was observed for Est-2 (females and males) and Aldox (only males). No significant differences were detected for allelic frequencies between sexes ( $G$-values ranged from 1.88 for Pept-2 in 1987 to 0.01 for $A d h-1$ in 1989) nor between years $(G=1.26$ for $A d h-1$ and $G=0.02$ for Pept-2) in any case. Table 2 shows the raw data for the female-male genotype combination at each locus on each day of sampling. The total numbers of flies in the collapsed mating tables differ from those given in Table 1 because it was not always possible to score both members of each mating pair.

Table 3 gives the $G$-value for the goodness of fit test for the various models (see Materials and Methods) together with the tests for the corresponding null hypotheses. Among-day genotypic frequencies of females and males were homogeneous for all loci in both years. In 1987, there were no departures from random mating for $A d h-1$, but female-male genotype combinations deviate from marginal expectations for Pept-2. Inspection of the mating tables for this locus indicated that significance was mostly due to the fifth day of collection. To test whether the diagonal counts were significantly larger than expected by chance, i.e. to test for positive assortative mating caused by inbreeding or assortment because of a common ancestral relationship, the kappa coefficient (also known as Cohen's measure of agreement; see Bishop et al., 1975; Kotz \& Johnson, 1983) for square two-way tables was computed in the female-male collapsed tables. There was neither evidence of assortment for Adh-1 or Pept2 , nor a clear pattern of deviations from random mating in the case of Pept-2. We concluded, therefore, that no obvious biological phenomenon was disturbing the expected mating frequency in the population from which samples were taken. In any case, we repeated the study in 1989 and increased the number of loci to four. The same analyses were carried out for each locus and the $G$-values are given on the right side of Table 3 . Note that random zeros occurred in the contingency

Table 1 Allele frequencies of wild mating D. buzzatii females and males, together with the deviation value $(D)$ from Hardy-Weinberg proportions (see text for details)

\begin{tabular}{|c|c|c|c|c|c|c|c|c|}
\hline \multirow[b]{2}{*}{ Year } & \multirow[b]{2}{*}{ Locus } & \multirow[b]{2}{*}{ Sex } & \multirow[b]{2}{*}{$n$} & \multicolumn{4}{|c|}{ Allele frequencies } & \multirow[b]{2}{*}{$D \dagger$} \\
\hline & & & & $a$ & $b$ & $c$ & $d$ & \\
\hline \multirow[t]{4}{*}{1987} & Pept-2 & 우 & 314 & 0.467 & 0.533 & & & -0.0043 \\
\hline & & $0^{*}$ & 346 & 0.504 & 0.496 & & & 0.0260 \\
\hline & Adh-I & \% & 308 & & 0.565 & 0.435 & & -0.0140 \\
\hline & & $\sigma^{*}$ & 312 & & 0.548 & 0.452 & & 0.0201 \\
\hline \multirow[t]{8}{*}{1989} & Pept-2 & Q & 349 & 0.471 & 0.529 & & & $0.0300^{*}$ \\
\hline & & $\sigma^{*}$ & 322 & 0.497 & 0.503 & & & 0.0140 \\
\hline & $A d h-1$ & \% & 332 & & 0.533 & 0.467 & & 0.0200 \\
\hline & & o & 298 & & 0.535 & 0.465 & & 0.0055 \\
\hline & Aldox & 웅 & 324 & 0.739 & 0.261 & & & -0.0186 \\
\hline & & 0 & 327 & 0.711 & 0.289 & & & $-0.0376^{* *}$ \\
\hline & $E s t-2$ & 웅 & 350 & 0.756 & 0.181 & 0.050 & 0.013 & $-0.0225^{*}$ \\
\hline & & o & 333 & 0.725 & 0.182 & 0.074 & 0.020 & $-0.0455^{* *}$ \\
\hline
\end{tabular}

$* P<0.05 ; * * P<0.001$.

$\dagger$ Alleles Est-2bs Est-2 , and $E s t-Z^{l}$ were pooled. 
Table 2 Frequencies of $D$. buzzatii wild mating pairs sampled at Carboneras. Rows stand for female genotypes (arranged according to faster migrating alleles; e.g. Pept- $2^{t / a}, P e p t-2^{u / h}$, and Pept- $\left.-2^{b / h}\right)$ and columns for male genotypes

\begin{tabular}{|c|c|c|c|c|c|c|c|c|c|c|c|c|c|c|c|c|c|c|}
\hline \multirow{3}{*}{$\frac{\text { Day }}{1}$} & \multicolumn{6}{|c|}{1987} & \multicolumn{12}{|c|}{1989} \\
\hline & \multicolumn{3}{|c|}{ Pept-2 } & \multicolumn{3}{|c|}{ Adh-l } & \multicolumn{3}{|c|}{ Pept-2 } & \multicolumn{3}{|c|}{$A d h-1$} & \multicolumn{3}{|c|}{ Aldox } & \multicolumn{3}{|c|}{ Est-2 } \\
\hline & 5 & 4 & 3 & 2 & 8 & 3 & 1 & 6 & 2 & 5 & 5 & 3 & 8 & 14 & 0 & 12 & 18 & 0 \\
\hline & 8 & 10 & 5 & 10 & 10 & 4 & 8 & 11 & 3 & 6 & 5 & 8 & 8 & 8 & 1 & 6 & 7 & 2 \\
\hline & 1 & 7 & 3 & 1 & 2 & 2 & 3 & 6 & 3 & 6 & 2 & 0 & 1 & 0 & 0 & 0 & 0 & 0 \\
\hline \multirow[t]{3}{*}{2} & 2 & 3 & 3 & 7 & 4 & 2 & 1 & 10 & 5 & 5 & 5 & 2 & 7 & 15 & 2 & 10 & 17 & 0 \\
\hline & 10 & 7 & 8 & 7 & 11 & 4 & 4 & 10 & 6 & 2 & 9 & 7 & 8 & 11 & 1 & 8 & 12 & 1 \\
\hline & 2 & 5 & 5 & 0 & 4 & 0 & 2 & 6 & 3 & 1 & 4 & 2 & 0 & 0 & 0 & 2 & 1 & 0 \\
\hline \multirow[t]{3}{*}{3} & 3 & 4 & 2 & 6 & 9 & 2 & 7 & 7 & 6 & 3 & 11 & 4 & 22 & 17 & 2 & 24 & 17 & 2 \\
\hline & 12 & 15 & 3 & 10 & 11 & 4 & 12 & 18 & 9 & 10 & 16 & 8 & 12 & 12 & 1 & 14 & 22 & 1 \\
\hline & 5 & 9 & 7 & 4 & 4 & 5 & 3 & 10 & 9 & 5 & 8 & 5 & 0 & 7 & 0 & 1 & 3 & 0 \\
\hline \multirow[t]{3}{*}{4} & 4 & 7 & 7 & 4 & 10 & 3 & 1 & 5 & 2 & 5 & 8 & 2 & 8 & 9 & 1 & 18 & 5 & 1 \\
\hline & 12 & 18 & 5 & 10 & 18 & 5 & 11 & 8 & 6 & 3 & 8 & 2 & 16 & 7 & 0 & 11 & 9 & 1 \\
\hline & 5 & 10 & 2 & 6 & 3 & 2 & 7 & 4 & 3 & 6 & 4 & 2 & 2 & 2 & 0 & 0 & 1 & 0 \\
\hline \multirow[t]{3}{*}{5} & 0 & 4 & 6 & 5 & 6 & 4 & 6 & 6 & 6 & 5 & 10 & 3 & 16 & 19 & 3 & 17 & 22 & 0 \\
\hline & 10 & 12 & 5 & 5 & 10 & 6 & 5 & 13 & 7 & 12 & 16 & 7 & 16 & 14 & 1 & 15 & 16 & 1 \\
\hline & 2 & 9 & 3 & 2 & 4 & 1 & 7 & 17 & 8 & 2 & 10 & 1 & 0 & 1 & 0 & 3 & 1 & 0 \\
\hline
\end{tabular}

Table $3 G$-values for models 1-4 and goodness of fit tests for two-factor effects

\begin{tabular}{|c|c|c|c|c|c|c|c|c|}
\hline \multirow[b]{2}{*}{ Model } & \multirow[b]{2}{*}{ d.f. } & \multicolumn{2}{|l|}{1987} & \multicolumn{5}{|l|}{1989} \\
\hline & & Pept-2 & Adh-1 & Pept -2 & Adh-1 & d.f. & Aldox & Est -2 \\
\hline 1 & 36 & 39.06 & 27.59 & 36.74 & 37.69 & 36 & 43.76 & 36.97 \\
\hline 2 & 32 & 26.39 & 26.60 & 34.49 & 34.44 & 28 & 36.62 & 33.34 \\
\hline 3 & 28 & 34.54 & 22.93 & 25.55 & 31.89 & 26 & 28.86 & 29.53 \\
\hline 4 & 28 & 32.70 & 25.05 & 26.31 & 26.80 & 28 & 37.28 & 27.56 \\
\hline \multicolumn{9}{|c|}{$\begin{array}{l}\text { Hypotheses tested } \\
\qquad H_{0}: \beta \gamma_{j k}=0 \text { for all } j k\end{array}$} \\
\hline & \multicolumn{8}{|c|}{$H_{0}: \alpha \beta_{i j}=0$ for all $i j$} \\
\hline$H_{0}: \alpha$ & \multicolumn{8}{|c|}{$H_{0}: \alpha \gamma_{i k}=0$ for all $i k$} \\
\hline & 8 & 6.36 & 2.54 & 10.43 & 10.89 & 8 & 6.48 & 9.41 \\
\hline $\begin{array}{l}\text { Kappa c } \\
\text { (SE) }\end{array}$ & nts $\dagger$ & $\begin{array}{r}-0.019 \\
(0.043)\end{array}$ & $\begin{array}{c}0.014 \\
(0.048)\end{array}$ & $\begin{array}{c}-0.013 \\
(0.041)\end{array}$ & $\begin{array}{r}-0.035 \\
(0.044)\end{array}$ & & $\begin{array}{r}-0.073 \\
(0.053)\end{array}$ & $\begin{array}{c}0.044 \\
(0.051)\end{array}$ \\
\hline
\end{tabular}

${ }^{*} P<0.05$.

$\dagger$ See text for details.

tables for Est-2 and Aldox (Table 2), so degrees of freedom in Table 3 were correspondingly modified (Brown $\&$ Fuchs, 1983). No significant $G$-value was detected this time and model 1 (i.e. complete independence of the three variables) seemed to fit the data perfectly well.

\section{Discussion}

Multi-locus studies of $D$. buzzatii natural populations in Australia have often shown heterozygote deficiency at enzyme loci and several explanations have been offered for this observation including the Wahlund 
effect or population subdivision, null alleles, and inbreeding (Barker \& Mulley, 1976; Barker et al., 1986; Sokal et al., 1987; Thomas \& Barker, 1990). The pattern that has emerged from these studies is that different loci do not show the same deficiency of heterozygotes, so it has been postulated that selection plays a role in determining genotypic frequencies in addition to inbreeding (Barker et al., 1986). In contrast to these findings, we have not observed a consistent deficiency of heterozygotes but an excess for the two loci known to be associated with the second-chromosome inversions (Est-2 and Aldox). A similar pattern to that observed in Table 1 emerges from samples of nonmating flies aspirated from Opuntia rots or collected by net from fermenting banana baits (to be published elsewhere).

The breeding structure of $D$. buzzatii is similar to that found for other drosophilids living upon nutritionally rich (yeast), yet relatively infrequent, substrates. Females possess numerous synchronously developing ovarioles and probably deposit a bunch of eggs (Santos et al., 1992). There are founder effects associated with the colonization of Opuntia rots, so the flies that emerge from a single substrate are more closely related than flies taken at random from the whole population (Santos et al., 1989; Thomas \& Barker, 1990). Under a neutral model of genetic differentiation, a general deficiency of heterozygotes is not expected unless more than one round of drift takes place; i.e. unless the flies emerging from a rotting cladode tend to stay and to mate rather than to disperse (Santos et al., 1989). Hence, the crucial point is to know whether or not an Opuntia rot remains as a suitable feeding and breeding site for two or more generations.

Most of the rots that develop in the late spring and early summer and are quite ephemeral, drying out in 6-8 weeks, as reported by Barker et al. (1983). We do not have a quantitative estimation of the period of time a rot remains as a suitable breeding site at Carboneras, but it seems clear that $O$. ficus-indica is a relatively fastrotting cactus. Variation in $\mathrm{pH}$ during the rotting process is swift and is highly correlated with yeast diversity; i.e. the number of yeast species increases with the age of a rot (F. Peris et al., unpublished observations). From field studies at Carboneras it was evident that the age of a rot (as measured by $\mathrm{pH}$ ) is a fairly good indicator of the age-structure of $D$. buzzatii immature stages. Thus, at $\mathrm{pH} 7.0-7.5$ all rots that had been previously colonized by $D$. buzzatii females mainly host second- and third-instar larvae. At $\mathrm{pH}$ 8.0-8.5, tan-coloured pupae can be seen around the cylinders of the dense and highly reticulate vascular system of the Opuntia cladodes, with the future imago easily noticeable in many of them. The observed synchronization between larval development and rotting process agrees with the fact that cactophilic Drosophila females lay their eggs early in the rotting process (Starmer et al., 1986). However, even if a rotting Opuntia cladode were no longer suitable for oviposition of the raised females, it does not necessarily imply that emerged adults would tend to disperse rather than to remain. This follows from the results of laboratory experiments with $D$. buzzatii, which are consistent with the hypothesis that adults are polyphagous on yeasts but have yeast preference for oviposition (Vacek et al., 1985). Although this situation could result in local random mating subpopulations followed by adult dispersion, the results of this paper clearly discard this possibility at least in the population of Carboneras.

The feasibility of a different situation at other times of the year, when environmental conditions and substrate availability are not the same, remains. Nevertheless, correlation coefficients for thorax length of male and female mating pairs were not statistically different from zero either in early summer or in mid fall (Santos et al., 1992). From a sample of newly emerging adults collected in the field, we have estimated that about 35 per cent of the total phenotypic variance for thorax length is accounted for the among-rot mean variation (M. Santos et al., unpublished observations). Therefore, local random mating of flies raised from a rot can be discarded again as it would result in positive assortative mating for body size in the whole population. In summary, from the traits studied there is strong evidence to conclude that under natural conditions $D$. buzzatii flies mate randomly.

\section{Acknowledgements}

We are indebted to Dr F. Peris and Mr A. Barbadilla for their excellent assistance during the course of the experiment. JEQ was supported by a research grant from the Instituto de Cooperación Iberoamericana (ICI). This work was supported by grants \# PB850071 and \# PB89-0325 to AF from the Dirección General de Investigación Científica y Técnica (DGICYT), Spain.

\section{References}

Alberola, J., SANCHEZ, A. AND FONTDEVIla, A. 1987. Adh expression in species of the mulleri subgroup of Drosophila. Biochem. Genet., 25, 729-738.

ALVAREZ, G. AND FONTDEVila, A. 1981. Selección sexual y apareamiento al azar en Drosophila melanogaster. Genét. Ibér., 33, 1-18. 
ANDERSON, w. w. 1974. Frequent multiple insemination in a natural population of D. pseudoobscura. Am. Nat., 108, 709-711

ANDERSON, w. W. AND MCGUIRE, P. R. 1978. Mating pattern and mating success of Drosophila pseudoobscura karyotypes in large experimental populations. Evolution, 32, $416-423$

BARker, J. S. F. 1977. Cactus-breeding Drosophila: A system for the measurement of natural selection. In: Christiansen, F. B. and Fenchel, T. M. (eds) Measuring Selection in Natural Populations, Springer-Verlag, Berlin.

BARKER, J. S. F. 1981. Selection at allozyme loci in cactophilic Drosophila. In: Gibson, J. B. and Oakeshott, J. G. (eds) Genetic Studies of Drosophila Populations. Proceedings of the 1979 Kioloa Conference, Australia National University, Canberra.

BARKER, J. S. F., EAST, P. D. AND WEIR, B. S. 1986. Temporal and microgeographic variation in allozyme frequencies in a natural population of Drosophila buzzatii. Genetics, 112. 577-611.

BARKER, J. S. F. AND MULLEY, J. C. 1976. Isozyme variation in natural populations of Drosophila buzzatii. Evolution, 30 , $213-233$

BARKER, J. S. F., TOLL, G. L., EAST. P. D., MIRANDA, M. AND PHAFF, H. J. 1983. Heterogeneity of the yeast flora in the breeding sites of cactophilic Drosophila. Can. J. Microbiol., 29, 6-14.

BISHOP, Y. M. M., FIENBERG, S. E. AND HOLLAND, P. w. 1975. Discrete Multivariate Analysis: Theory and Practice. MIT Press Cambridge, MA.

BMDP 1988. Statistical Software. University of California Press, Berkeley, CA.

BRown, A. H. D. 1970. The estimation of Wright's fixation index from genotypic frequencies. Genetica , 41, 399-406.

BROWN, M. B. AND FUCHS, C. 1983. On maximum likelihood estimation in sparse contingency tables. Comp. Statist. Data Analysis, 1, 3-15.

CoBBs, G. 1977. Multiple insemination and male sexual selection in natural populations of Drosophila pseudoobscura. Am. Nat., 111, 641-656.

FALK, C. AND EHRMAN, L. 1973. Random mating revisited. Behav. Genet., 3, 91-95.

GROMKO, M. H., SHEEHAN, K. AND RICHMOND, R. C. 1980. Random mating in two species of Drosophila. Am. Nat., 115, 467-479.

KNIBB, W. R., EAST, P. D. AND BARKER, J. S. F. 1987. Polymorphic inversion and esterase loci complex on chromosome 2 of Drosophila buzzatii. I. Linkage disequilibria. Aust. J. Biol. Sci., 40, 257-269.

KOTZ, S. AND JOHNSON, N. L. (eds) 1983. Encyclopedia of Statistical Sciences, Vol. 4. John Wiley \& Sons, New York.

LABRADOR, M., NAVEIRA, H. AND FONTDEVILA, A. 1990. Genetic mapping of the Adh locus in the repleta group of Drosophila by in situ hybridization. J. Hered., 81, 83-86.

LEVINE, L., ASMUSSEN, M., OLVERA, O., POWELL, J. R., DE LA ROSA, M. E., SALCEDA, V. M., GASSO, M. I., GUZMÁN, J. AND ANDERSON, W. W. 1980. A high rate of multiple insemination in a natural population of Drosophila pseudoobscura. Am. Nat., 116, 493-503.

LEWONTIN, R. C. AND COCKERHAM, C. C. 1959. The goodness-of- fit test for detecting natural selection in random mating populations. Evolution, 13, 561-564.

LEWONTIN, R. C., KIRK, D. AND CROW, J. 1968. Selective mating, assortative mating, and inbreeding: definitions and implications. Eugenics Quart., 15, 141-143.

LI, C. C. 1988. Pseudo-random mating populations. In celebration of the 80th anniversary of the Hardy-Weinberg law. Genetics, 119, 731-737.

LOUKAS, M. AND KRIMBAS, C. B. 1980 . Isozyme techniques in $D$. subobscura. Dros. Inform. Serv., 55, 157-158.

LOUKAS, M., VERGINI, Y. AND KRIMBAS, C. B. 1981. The genetics of Drosophila subobscura. XVIII. Multiple insemination and sperm displacement in Drosophila subobscura. Genetica, 57, 29-37.

MILKMAN, R. AND ZEITLER, R. R. 1974. Concurrent multiple paternity in natural and laboratory populations of Drosophila melanogaster. Genetics, 78, 1191-1193.

OAKESHOTT, J. G., CHAMBERS, G. K., EAST, P. D., GIBSON, J. B. AND BARKER, J. S. F. 1982. Evidence for a genic duplication involving alcohol dehydrogenase genes in Drosophila buzzatii and related species. Aust. J. Biol. Sci., 35, 73-84.

o'Donald, P. 1980. Genetic Models of Sexual Selection. Cambridge University Press, Cambridge.

PARTRIDGE, L., HOFFMAN, A. AND JONES, J. S. 1987. Male size and mating success in Drosophila melanogaster and Drosophila pseudoobscura under field conditions. Anim. Behav., 35, 468-476.

RUIZ, A., FONTDEVILA, A., SANTOS, M., SEOANE, M. AND TORROJA, E. 1986. The evolutionary history of Drosophila buzzatii VIII. Evidence for endocyclic selection acting on the inversion polymorphism in a natural population. Evolution, 40, 740-755.

RUIZ, A., SANTOS, M., BARBADILlA, A., QUEZADA-DIAZ, J. E. HASSON, E. AND FONTDEVILA, A. 1991. Genetic variance for body size in a natural population of Drosophila buzzatii. Genetics 128, 739-750.

SANTOS, M., RUIZ, A., BARBADILlA, A., QUEZADA-DfAZ, J. E., HASSON E. AND FONTDEVILA, A. 1988. The evolutionary history of Drosophila buzzatii. XIV. Larger flies mate more often in nature. Heredity, 61, 255-262.

SANTOS, M., RUIZ, A. AND FONTDEvila, A. 1989. The evolutionary history of Drosophila buzzatii. XIII. Random differenciation as a partial explanation of the observed chromosomal variation in a structured natural population. Am. Nat., 133, 183-197.

SANTOS, M., RUIZ, A., QUEZADA-DÍAZ, J. E., BARBADILLA, A. AND Fontdevila, A. 1992. The evolutionary history of Drosophila buzzatii. xx. Positive phenotypic covariance between field adult fitness components and body size. J. Evol. Biol. (in press)

SANTOS, M., TARRIO, R., ZAPATA, C. AND ALVAREZ, G. 1986. Sexual selection on chromosomal polymorphism in Drosophila subobscura. Heredity, 57, 161-169.

SOKAL, R. R., ODEN, N. L. AND BARKER, J. S. F. 1987. Spatial structure in Drosophila buzzatii populations: simple and directional spatial autocorrelation. Am. Nat., 129, 122-142.

SOKAL, R. R. AND ROHLF, F. J. 1981. Biometry (2nd edn). Freeman, San Francisco.

STARMER, W. T., BARKER, J. S. F., PHAFF, H. J. AND FOGLEMAN, J. C. 
1986. Adaptations of Drosophila and yeasts: their interactions with the volatile 2-propanol in the cactus-microorganism-Drosophila model system. Aust. J. Biol. Sci., 39, 69-77.

TAI, J. J. 1990. On nonrandom mating systems for attaining Hardy-Weinberg equilibrium. Biom. J., 32, 1005-1014.

THOMAS, R. AND BARKER, J. S. F. 1990. Breeding structure of natural populations of Drosophila buzzatii: effects of the distribution of larval substrates. Heredity, 64, 355-365.
VACEK, D. C., EAST, P. D., BARKER, J. S. F. AND SOLIMAN, M. H. 1985. Feeding and oviposition preferences of Drosophila buzzatii for microbial species isolated from its natural environment. Biol. J. Linn. Soc., 24, 175-187.

WARD, R. H. AND SING, C. F. 1970. A consideration of the power of the $\chi^{2}$ test to detect inbreeding effects in natural populations. Am. Nat., 104, 355-365.

weIR, B. S. 1990. Genetic Data Analysis. Sinauer Associates, MA. 